Psychic Impotence. (Psycho-analytic Review, vol. xx, p. 274, July, 1933.) Karpman, $B$.

Disregarding the small number of cases with a physical basis, impotence is an hysterical conversion mechansim, of psychic causation, and, as a rule, improves rapidly following a rational psycho-therapy. Mechanical, medical and surgical treatments are ineffectual, and the first is dangerous. Lack of domestic harmony, an unappealing love-object or divided love may all bring about disturbance of potency. Fears of the consequences of masturbation or of sexual excess are frequent causal factors; such fears are totally unfounded. In other cases an incestuous attachment or homosexual leaning is found to be responsible. Ejaculatio præcox is usually conditioned on some strong emotion, such as fear and anxiety of an unconscious origin. Morning erections are due to erotic dreams, and not to the reflex actions of a distended bladder as is popularly supposed.

Stanley M. Coleman.

Paraldehyde Addiction. (Brit. Journ. of Inebriety, vol. xxxi, 1933.) Carver, A. E.

The rarity of paraldehydism is over-estimated; the author has treated 18 cases during the past eight years. Paraldehydism never occurred as the sole addiction, but always a complication (usually late) of other addictions, especially of alcoholism. Those addicted to any drug invariably have an abnormal mental make-up. An interesting question is why (apart from ease of access) a patient becomes addicted to any particular drug. To render difficult of access any one drug merely brings another into popularity; restrictions may deviate the impulse, they do not cure it. But the medical profession should exercise greater care in introducing habit-forming drugs to patients. The term "drug'ist" is suggested as a title for one who is immoderately addicted to the taking of any drug.

M. Hamblin Smith.

The Significance of the Complaint Factor in Child Psychiatry. (Amer. Journ. Psychiat., vol. xiii, p. I7I, July, I933.) Kanner, L.

The complaint made by the person who brings the child is of great importance in making the approach to the case. (The child's own contribution to the complaint is also solicited, always in the absence of the parents.) The complaint lends itself as a centre for systematic grouping of the symptoms. Instead of subscribing to any fixed set of diagnostic vocabulary, we come to view diagnosis as a reformulation of the complaint. The complaint factor also serves as a valuable indication of therapeutic success.

M. Hamblin Smith

\title{
4. Neurology.
}

Cataplexy. (Journ. of Neur. and Psychopathol., vol.xiv, p. 45, July, 1933.) Kinnier Wilson, S. A.

The writer gives an account of what is probably the first described case of status cataplecticus lasting 14 minutes. The plantar reflex was abolished. He points out that there is some radiation of the original affective impulse from an emotional " centre " to a number of somatic and visceral " centres ". The " storm centre" of the cataplectic seizure appears to be thalamic, with immediate spread to the cortex in part and to the hypothalamus and ventricular floors in part. The emotion which is so profound as to cause relaxation of the sphincters does not appear to characterize cataplexy. It seems that the mechanism once used by fear to produce motionlessness can also be activated by an emotion of opposite quality. The question of unexpectedness is important; cortico-thalamic inhibition appears to have greater momentum than cortico-cortical, so that if the subject is prepared beforehand, the cataplectic attack may not materialize.

G. W. T. H. Fleming. 